\title{
In vitro and in vivo antitumor activity of cetuximab in human gastric cancer cell lines in relation to epidermal growth factor receptor (EGFR) expression and mutational phenotype
}

\author{
Birgit Hotz • Ulrich Keilholz • Alberto Fusi • \\ Heinz J. Buhr • Hubert G. Hotz
}

Received: 23 June 2011 / Accepted: 14 September 2011/Published online: 20 October 2011

(C) The International Gastric Cancer Association and The Japanese Gastric Cancer Association 2011

\begin{abstract}
Background Targeting the epidermal growth factor receptor (EGFR) pathway is an important approach for a variety of tumors. This study assessed the effect of cetuximab, an anti-EGFR monoclonal antibody, on three gastric cancer cell lines with different phenotypes in vitro and in a therapeutic orthotopic murine gastric cancer model.

Methods Three human gastric cancer cell lines (AGS, MKN-45, NCI-N87) were evaluated for cell surface EGFR expression, and K-ras and BRAF mutations. In vitro, the effects of cetuximab, carboplatin, irinotecan, and docetaxel were investigated. Orthotopic tumors derived from MKN45 and NCI-N87 were established in nude mice. After 4 weeks, the animals received cetuximab $(1 \mathrm{mg} / \mathrm{kg}$, weekly i.p.) or carboplatin ( $20 \mathrm{mg} / \mathrm{kg}$, weekly i.p.), or both agents. The volume of the primary tumor and local and systemic tumor spread were determined at autopsy at 14 weeks. Tumor sections were immunostained for EGFR, as well as stained for CD31 to analyze microvessel density.

Results Cell surface expression of EGFR was found only in AGS and NCI-N87 cells. AGS cells displayed a codon $12 \mathrm{~K}$-ras mutation, and all three cell lines were BRAF wild-type. In vitro, cetuximab significantly reduced cell viability and proliferation only in EGFR-positive/K-ras wild-type NCI-N87 cells $(-48 \%)$. In vivo, cetuximab in combination with carboplatin synergistically reduced
\end{abstract}

B. Hotz · H. J. Buhr · H. G. Hotz ( $)$

Department of Surgery, Charité-School of Medicine,

Campus Benjamin Franklin, Hindenburgdamm 30,

12203 Berlin, Germany

e-mail: hubert.hotz@charite.de

U. Keilholz · A. Fusi

Department of Hematology and Oncology, Charité-Medical

School Berlin, Campus Benjamin Franklin, Berlin, Germany tumor volume $(-75 \%)$, dissemination $(-63 \%)$, and vascularization $(-47 \%)$ in NCI-N87 xenografts. Tumors derived from EGFR-negative MKN-45 cells were unaffected by cetuximab.

Conclusions Cetuximab is effective in K-ras wild-type, EGFR-expressing gastric cancer cell lines and xenografts. In vivo, the combination of cetuximab with carboplatin displayed synergistic antitumor activity.

Keywords Gastric cancer - EGFR - Cetuximab · Carboplatin · Orthotopic mouse model

\section{Introduction}

Gastric cancer is one of the most common cancer types in the western world. The majority of stomach cancers are adenocarcinomas and they are associated with high mortality, as many patients present with locally advanced or metastatic disease, and treatment options are limited [1]. Apart from potentially curative surgery, chemotherapy as well as radiochemotherapy may be applied, but these modalities do not cure this disease [2]. Although recent efforts to improve the treatment of gastric cancer were promising, the outcome of advanced disease is still disappointing. Targeted agents are therefore being investigated to improve the clinical outcome of gastric cancer patients.

Epidermal growth factor receptor (EGFR) is involved in malignant transformation and tumor growth through the inhibition of apoptosis, cellular proliferation, promotion of angiogenesis, and metastasis. EGFR is abnormally activated in many types of epithelial tumors and this typically correlates with aggressive tumor growth, as well as with poor clinical outcome [3,4]. In gastric cancer, EGFR is overexpressed in $18-91 \%$ of primary tumors [5]. Ligand 
binding of the EGFR activates the Ras/Raf/MAPK, STAT, and PI3K/AKT signaling pathways, which modulate cellular proliferation, angiogenesis, and survival. Cetuximab (C-225, Erbitux; Merck, Darmstadt, Germany) is a welldeveloped anti-EGFR monoclonal antibody and has been approved for clinical use in patients with metastatic colorectal cancer $[6,7]$. It binds to the extracellular domain of EGFR with high affinity. It competitively blocks ligand binding and inhibits tyrosine kinase activation, resulting in receptor downregulation [8]. Apart from this competitive inhibition, cetuximab binding with EGFR might trigger internalization and destruction of the receptor [9]. Preclinical studies have shown that cetuximab is able to inhibit the growth of colon and pancreatic carcinoma cell lines and xenografts in animals $[10,11]$. Available data also suggest a significant synergy with different cytotoxics and radiotherapy [12-14]. However, cetuximab is ineffective in patients with colorectal cancer bearing mutations in the K-ras gene, which is part of the EGFR signaling pathway $[15,16]$. Mutated ras is constitutively activated, even when the EGFR is blocked. Together with K-ras, BRAF, a downstream gene of the RAS pathway, is also known to be somatically mutated in a number of human cancers, and BRAF mutations have been associated with resistance to EGFR-targeted antibody therapies [17].

In the present study we therefore evaluated first the status of cell surface EGFR, K-ras, and BRAF mutations in the human gastric cancer cell lines AGS, MKN-45, and NCI-N87. Cell viability and proliferation was measured after treatment with cetuximab and different chemotherapeutics (carboplatin, irinotecan, and docetaxel) in vitro. According to the in vitro results we further investigated the therapeutic potential of cetuximab, either as monotherapy or combined with carboplatin, against MKN-45 (EGFRnegative, K-ras wild-type) and NCI-N87 (EGFR-positive, K-ras wild-type) xenografts in vivo, using an orthotopic model of human gastric carcinoma in nude mice. In addition we analyzed the microvessel density (MVD) of the orthotopic tumors by immunohistochemistry, as EGFR blockade with cetuximab may also inhibit angiogenesis [18].

\section{Materials and methods}

\section{Cell lines and culture conditions}

The gastric adenocarcinoma cell lines AGS (poorly differentiated), MKN-45 (poorly differentiated), and NCIN87 (well differentiated) were used for this study. The cell lines were obtained from the European Collection of Cell Cultures (ECACC; Salisbury, UK) and cultured in DMEM medium (AGS) or RPMI-1640 (MKN45, N87) (PAA
Laboratories, Cölbe, Germany), supplemented with $10 \%$ fetal calf serum (FCS-Gold, PAA Laboratories), penicillin $\mathrm{G}(100 \mathrm{U} / \mathrm{ml})$, streptomycin $(100 \mu \mathrm{g} / \mathrm{ml})$, and amphotericin B $(0.25 \mathrm{mg} / \mathrm{ml})$. Cells were incubated at $37^{\circ} \mathrm{C}$ in humidified air with $5 \% \mathrm{CO}_{2}$. The medium was replaced three times a week, and cells were maintained by serial passaging after trypsinization with $0.1 \%$ trypsin.

Agents

The agents used were cetuximab (Erbitux ${ }^{\circledR}$; Merck), irinotecan (Campto ${ }^{\circledR}$; Pfizer, Berlin, Germany), carboplatin (GRY-Pharma, Kirchzarten, Germany), and docetaxel (Taxotere $^{\circledR}$; Sanofi-Aventis, Berlin, Germany).

Reverse transcriptase polymerase chain reaction (RT-PCR)

Total cellular RNA was extracted from cell cultures, using the NucleoSpin RNA II-Kit (Macherey \& Nagel, Düren, Germany) according to the manufacturer's instructions, and resuspended in $50 \mu \mathrm{l}$ of dimethylpyrocarbonate-treated water. The RNA concentration was determined using a BioPhotometer (Eppendorf Scientific, Hamburg, Germany). Total RNA $(2 \mu \mathrm{g})$ was primed with an oligo(dT) oligonucleotide and reverse-transcribed with M-MLV reverse transcriptase (Promega, Mannheim, Germany) and dNTPs (Sigma-Aldrich, Seelze, Germany) according to the manufacturer's instructions. First-strand cDNA was amplified with transcript-specific oligonucleotides using Ready-Mix Taq PCR Reaction Mix (Sigma-Aldrich).

The primers (TIB MOLBIOL, Berlin, Germany) for the respective genes were designed as follows-EGFR, sense: 5'-TAC CTA AGG ATA GCA CCG C-3'; antisense: 5' TAC AAA GGA CTG CTG TTA ACC A- $3^{\prime}$. $\beta$-actin, sense: $5^{\prime}$-TTC CTG GGC ATG GAG TCC TGT GG-3'; antisense: 5'-CGC CTA GAA GCA TTT GCG GTG G-3'.

The PCR products and a 1-kb DNA molecular weight marker were electrophoresed on a $1 \%$ agarose gel. The gel was then visualized and photographed under ultraviolet light.

Flow cytometry (fluorescence activated cell sorting [FACS])

Cells from the human gastric cancer cell lines AGS, MKN45, and NCI-N87 were harvested with trypsin/ethylenediamine tetraacetic acid (EDTA) and washed three times with FACS buffer (phosphate-buffered saline [PBS] supplemented with $1 \%$ FCS) to completely remove culture medium. Then $2 \times 10^{5}$ cells were resuspended in $50 \mu \mathrm{l}$ FACS buffer and blocked with $10 \mu \mathrm{FcR}$ (FcR blocking reagent; Miltenyi Biotec, Bergisch Gladbach, Germany) for $10 \mathrm{~min}$ at $4^{\circ} \mathrm{C}$. The suspension was divided into two 
fractions and stained with $10 \mu \mathrm{l}$ of a rat monoclonal EGFR antibody conjugated with APC (clone 423103; R\&D System, Wiesbaden, Germany) or with $10 \mu \mathrm{l}$ of an isotype control antibody conjugated with APC (rat $\operatorname{IgG}_{2 \mathrm{a}} ; \mathrm{R} \& \mathrm{D}$ System). The labeled cells were then washed and the intensity of fluorescence was evaluated by a flow cytometer, FACSCalibur (BD Biosciences, San José, CA, USA) and the data were analyzed with the use of FlowJo 7.2.5 software (Tree Star, Ashland, OR, USA).

Mutation analysis

DNA isolation from the gastric cell lines AGS, MKN-45, and NCI-N87 was performed using the QiAmp DNA-Isolation Kit (Qiagen, Hilden, Germany) according to the manufacturer's instructions.

\section{BRAF}

BRAF mutations in codon 600 were evaluated. LightCycler (Roche Diagnostics, Mannheim, Germany) PCR mutation analysis was performed with the oligonucleotides listed in Table 1. Oligonucleotides were added to LightCycler DNA Master Hybridization Probe mixture (Roche Diagnostics) in the following final concentrations: primers $0.5 \mathrm{mmol} / \mathrm{L}$, anchor and sensor $0.2 \mathrm{mmol} / \mathrm{L}$. The final $\mathrm{MgCl}_{2}$ concentration was $3 \mathrm{mM}$. PCR was performed with the following temperature/time protocol: denaturation, $95^{\circ} \mathrm{C}$ for $1 \mathrm{~s}$ in the first cycle; denaturation, $95^{\circ} \mathrm{C}$ for $0 \mathrm{~s}$ in further cycles; annealing, $64^{\circ} \mathrm{C}$ for $12 \mathrm{~s}$; elongation, $72^{\circ} \mathrm{C}$ for $6 \mathrm{~s}$, with a transition rate of $20^{\circ} \mathrm{C} / \mathrm{s}$ between temperature plateaus for a total of 50 cycles. Thereafter, melting curve analysis of amplicons was performed, starting from $45^{\circ} \mathrm{C}$ and proceeding until $85^{\circ} \mathrm{C}$ at a linear rate of $0.3^{\circ} \mathrm{C} / \mathrm{s}$. Data were analyzed by means of the LightCycler Data Analysis software (version 3; Roche Diagnostics).

\section{K-ras}

Polymerase chain reactions for K-ras exon-1 amplification were conducted using the oligonucleotide primers listed in Table 1. The PCR was performed at $55^{\circ} \mathrm{C}$ for 35 cycles. Electrophoresis in a $1.5 \%$ agarose gel confirmed amplification of 150-bp DNA fragments. The PCR products were then submitted to direct sequencing, using the same primers as those described above. The resulting sequences were compared with the K-ras sequence deposited in GenBank databases.

In vitro assessment of cell proliferation and viability

To examine the effect of cetuximab on in vitro cell proliferation, $2 \times 10^{5}$ cells from the AGS, MKN-45, and NCIN87 cell lines were seeded in six-well culture plates in $2 \mathrm{ml}$ of the respective cell culture medium. The medium was changed the next day (day 1) and cetuximab was added at the following concentrations: 1, 10, and $100 \mu \mathrm{g} / \mathrm{ml}$. After $72 \mathrm{~h}$ (day 4), the cells were trypsinized and counted in a standard hemocytometer. Cell viability was assessed by a colorimetric dye reduction assay with monotetrazolium (MTT; Boehringer, Mannheim, Germany) according to the manufacturer's instructions. Briefly, cells were seeded in 96-well plates at a density of $3 \times 10^{3}$ cells in $0.2 \mathrm{ml}$ of the respective medium. Medium was changed the next day (day 1) and cetuximab was added as described above. After $72 \mathrm{~h}$ (day 4), $10 \mu \mathrm{l}$ of MTT $(5 \mathrm{mg} / \mathrm{ml})$ solution, and after an additional $4 \mathrm{~h}, 100 \mu \mathrm{l}$ of $10 \%$ sodium dodecylsulfate (SDS) were added to the cells. The plates were allowed to stand overnight $\left(37^{\circ} \mathrm{C}, 5 \% \mathrm{CO}_{2}\right)$. The change in absorbance measured at $550 \mathrm{~nm}$ with a microplate reader (Biotek Instruments, Burlington, VT, USA) has been shown to strongly correlate with the number of viable cells. In a second approach, the three human gastric cancer cell lines were exposed to the cytostatic agents carboplatin $(30,300$, and $3000 \mu \mathrm{g} / \mathrm{ml})$, irinotecan $(10,100$, and $1000 \mu \mathrm{g} / \mathrm{ml})$, and docetaxel $(3,30$, and $300 \mu \mathrm{g} / \mathrm{ml})$. Proliferation and cell viability was measured as described above. All experiments were performed in triplicates.

Laboratory animals and orthotopic implantation technique

A previously established nude mouse model for human gastric cancer [19] was employed for in vivo studies. Fourweek-old male CD-1 nude mice (CD-1/nu-nu) weighing 20-30 g were obtained from Charles River Laboratories (Sulzfeld, Germany) and were cared for in accordance with
Table 1 Primer sequences for mutation analysis

\begin{tabular}{ll}
\hline Primer & Sequence $5^{\prime}-3^{\prime}$ \\
\hline BRAF forward & ATATTTCTTCATGAAGACCTCACAGTAA \\
BRAF reverse & GCATATACATCTGACTGAAAGC \\
Anchor & LCRed640-CAGAGAAATCTCGATGGAGTGGGT-phosphate \\
Sensor & CATCAGTTTGAACAGTTGTCTGGATCCATTTTGT-fluorescein \\
K-ras forward & GACTGAATATAAACTTGTGG \\
K-ras reverse & CTGTATCAAAGAATGGTCCT \\
\hline
\end{tabular}


the standards of the German Council on Animal Care, under an approved protocol of the local Animal Welfare Committee. The animals were housed in type IV cages with food and water available ad libitum. Donor nude mice were anesthetized with isoflurane (Forene; Abbott, Wiesbaden, Germany) inhalation. Then $5 \times 10^{7}$ cells of the MKN-45 or NCI-N87 human gastric cancer cell lines were injected subcutaneously into the animals' flanks. Mice were sacrificed after 4 weeks (when the subcutaneous tumors had reached a size of $1 \mathrm{~cm}$ in largest diameter) by inhalation of isoflurane, followed by opening of the thorax and removal of the heart. The donor tumors were harvested under strict aseptic conditions and minced with a scalpel (no. 11) into small $\left(1-\mathrm{mm}^{3}\right)$ fragments. To avoid necrotic tissue from central tumor areas, only macroscopically viable tumor tissue from the outer part of the donor tumors was used for orthotopic implantation.

Tumor recipient nude mice were anesthetized with an intraperitoneal injection of xylazine hydrochloride (Rompun, $12 \mathrm{mg} / \mathrm{kg}$ body weight [BW]; Bayer, Leverkusen, Germany) and esketamine hydrochloride (Ketanest S, 40 mg/kg BW; Parke-Davis/Pfizer, Karlsruhe, Germany). The animals' abdomens were opened by a midline incision under aseptic conditions and the stomach was gently exteriorized. One small tissue pocket was prepared in the submucosa of the distal stomach using microscissors (RS-5610 VANNAS; Roboz, Rockville, MD, USA). One donor tumor fragment was placed into the gastric tissue pocket and fixed with one drop of tissue adhesive (Histoacryl; B. Braun, Tuttlingen, Germany). The stomach was relocated into the abdominal cavity, which was then closed in 2 layers with 4-0 absorbable suture (Ethicon, Norderstedt, Germany).

For pain relief, a subcutaneous injection of carprofen $\left(\right.$ Rimadyl ${ }^{\circledR} ; 4 \mathrm{mg} / \mathrm{kg} \mathrm{BW}$; Pfizer) was given after surgery.

In vivo treatment with cetuximab and carboplatin

The animals were allocated randomly to three treatment groups and a control group (12 animals per group). Treatment began 4 weeks after tumor implantation, using the following drug doses and treatment schedules-group 1: cetuximab $1 \mathrm{mg} / \mathrm{animal}$, i.p. once a week; group 2 : carboplatin $20 \mathrm{mg} / \mathrm{kg}$ body weight, i.p. once a week; group 3: cetuximab (1 mg/animal) and carboplatin $(20 \mathrm{mg} / \mathrm{kg})$, i.p. once a week; group 4: control mice were treated with $0.9 \%$ saline, i.p. once a week. The mice were monitored daily to evaluate their clinical conditions.

Observation period, assessment of primary tumor size, and dissemination score

Fourteen weeks after transplantation, the animals were sacrificed and an autopsy was performed to examine the growth of the tumors. The perpendicular diameters of the primary orthotopic tumor were measured with calipers, and the volume was calculated using the following formula: volume $=$ length $\times$ width $\times \operatorname{depth} / 2$. A dissemination score was used to assess local tumor infiltration as well as distant metastasis [20]. Local infiltration was determined at the following sites: liver, pancreas, mesentery, bowel loops, and abdominal wall. Isolated tumor nodules with no anatomic connection to the primary tumor were judged as distant metastases. Tumor dissemination was quantified as follows: every manifestation of tumor infiltration or metastasis was given one point. Additional points were given for massive local infiltration (e.g., including more than half of the circumference of the pancreas), multiple metastatic nodules ( $>1$ in parenchymal organs; $>10$ on diaphragm, mesentery, retroperitoneum), and metastatic nodules $>50 \mathrm{~mm}^{3}$. The clinical consequences of the tumor growth (formation of ascites [2 points if volume $>5 \mathrm{ml}$ ], and the development of jaundice, ileus, and cachexia) were incorporated into this scoring system The primary tumor and all sites of potential infiltration or metastasis were harvested, fixed in $4 \%$ formaldehyde, and embedded in paraffin. Then $3-\mu \mathrm{m}$-thick tissue sections were obtained and stained with hematoxylin and eosin for microscopic examination. The sections were reviewed to confirm the findings of the macroscopic dissemination score.

\section{Immunohistochemistry}

Immunohistochemical staining was performed on paraffinembedded tissue. Three-micrometer-thick sections were cut, using a rotation microtome (Leica, Nussloch, Germany, RM2125RT;). The sections were deparaffinized in xylene and rehydrated in graded alcohols and distilled water. After antigen retrieval with $0.01 \%$ EDTA pH 8.0, endogenous peroxidase activity was blocked with $1 \%$ hydrogen peroxide in distilled water for $25 \mathrm{~min}$, followed by washing with distilled water and finally washing with PBS $+0.1 \%$ Tween for 5 min. To bind nonspecific antigens, the sections were incubated with $1 \times$ Power Block (BioGenex, San Ramon, CA, USA) for $5 \mathrm{~min}$. The primary antibodies, EGFR (polyclonal rabbit), and CD31 (polyclonal goat), were purchased from Santa Cruz Biotechnology (Santa Cruz, CA, USA). Antibody dilution was 1:100 (EGFR), and 1:150 (CD31) in antibody dilution buffer (DCS LabLine, Hamburg, Germany) for $30 \mathrm{~min}$ at $37^{\circ} \mathrm{C}$. As a negative control, sections were incubated with antibody dilution buffer instead of the primary antibody. This was followed by incubation with biotinylated antirabbit or anti-goat immunoglobulin G (1:200, Santa Cruz) for $30 \mathrm{~min}$ at $37^{\circ} \mathrm{C}$ and peroxidase-conjugated avidinbiotin complexes (KPL, Gaithersburg, MD, USA) and 3,3'diaminobenzidine (Sigma-Aldrich). The sections were then 
counterstained with Mayer's hematoxylin, upgraded alcohols, mounted, and analyzed by standard light microscopy. Immunostaining assessment for EGFR was performed regarding the staining intensity, using a fourpoint scale $(0=$ negative, $+=$ weak,$++=$ moderate, $+++=$ strong).

Microvessel density was quantified as described by Weidner [21]. Areas of highest neovascularization were found by scanning the sections at a magnification of $100 \times$; individual microvessel counts were then made on fields at $200 \times$ magnification $\left(\approx 0.74 \mathrm{~mm}^{2}\right.$ per field).

\section{Statistical analysis}

Data are presented as means \pm SEM. Continuous, normally distributed variables were analyzed by Student's $t$-test. Discontinuous variables (dissemination score) were analyzed by the Mann-Whitney rank sum test. The survival data were analyzed by Kaplan-Meier test, and the survival periods were compared by the log-rank test. Differences were considered statistically significant at a $p$ value of $<0.05$.

\section{Results}

EGFR mRNA and surface expression in tumor cell lines

All three gastric cancer cell lines were evaluated to obtain the baseline levels of EGFR. As shown by RT-PCR, all three cell lines expressed EGFR at the mRNA level (Fig. 1a), whereas FACS analysis revealed different levels of cell surface EGFR expression in the gastric cancer cell lines (Fig. 1b). In AGS we detected two cell populations, one positive for EGFR and one negative. The cell line MKN-45 was negative for EGFR cell surface expression and all NCI-N87 cells showed surface expression of EGFR. Immunohistochemical analysis of tumor xenografts confirmed membrane EGFR expression on NCI-N87 cells in vivo (Fig. 1d). However, corresponding to the mRNA expression, the cell line MKN-45, which was negative for cell surface EGFR, revealed weak cytoplasmic staining.

BRAF and K-ras mutation analysis

All three cell lines AGS, MKN-45, and NCI-N87 were tested for the presence of point mutations in BRAF (exon 15, codon 600, p.V600E GTG $\rightarrow$ GAG, p.V600K GTG $\rightarrow$ AAG, p.600R GTG $\rightarrow$ AGG) by melting curve analysis, and the presence of point mutations in K-ras (exon 1, codons 12 and 13) was tested by direct sequencing. No BRAF point mutation was found in any of the cell lines. A K-ras point mutation was found only in the cell line AGS (GGT $\rightarrow$ GAT at codon
12, Gly $\rightarrow$ Asp). MKN-45 and N87 displayed no K-ras mutations at codons 12 or 13 .

Effects of cetuximab, carboplatin, irinotecan, and docetaxel on cell viability and proliferation in vitro

The effects of cetuximab and the chemotherapeutic agents carboplatin, irinotecan, and docetaxel on the viability and proliferation of the human gastric cancer cell lines AGS, MKN-45, and NCI-N87 were studied over a time period of 72 h. Figure 2 shows the proliferation and viability changes during drug treatment. For statistical calculations, untreated control cells were set at $100 \%$ viability and proliferation. Cetuximab at concentrations from 1 to $10 \mu \mathrm{g} /$ ml was neither cytotoxic nor cytostatic. Only the cell line NCI-N87 showed decreased proliferation (62.9\%) at $10 \mu \mathrm{g} /$ $\mathrm{ml}$ cetuximab. Higher concentrations, up to $100 \mu \mathrm{g} / \mathrm{ml}$, reduced cell viability significantly in all three cell lines (AGS 81.8\%, MKN-45 83.8\%, NCI-N87 88.7\%). While proliferation was reduced to $79.9 \%$ in $\mathrm{MKN}-45$ cells and to $52.8 \%$ in NCI-N87 cells, the proliferation of AGS cells was not affected by cetuximab even at the highest concentration (100 $\mu \mathrm{g} / \mathrm{ml})$ (Fig. 2a).

The chemotherapeutic agents carboplatin, irinotecan, and docetaxel significantly inhibited cell viability and proliferation in all the gastric cancer cell lines in a dosedependent manner (Fig. 2b-d). Increasing concentrations of carboplatin $(30,300,3000 \mu \mathrm{g} / \mathrm{ml})$ reduced the cell viability of AGS cells to $61.9,57.1$, and $42.9 \%$, respectively; that of MKN-45 cells to 40.7, 42.4, and $15.3 \%$, and that of NCI-N87 cells to 79.2, 66.7, and 33.3\%. Proliferation declined in AGS cells to 67.4, 30.6, and 0\%; in MKN-45 cells to $67.9,0.9$, and $0 \%$; and in NCI-N87 cells to 66.5 , 15 , and $0.6 \%$. Treatment with irinotecan $(10,100,1000 \mu \mathrm{g} /$ $\mathrm{ml})$ led to decreased cell viability in AGS cells to 90.9, 50, and 45.5\%; in MKN-45 cells to 55.4, 33.9, and 19.6\%; and in NCI-N87 cells to 68, 52, and $36 \%$. Proliferation dropped in AGS cells to 29.3, 1.38, and 0\%, in MKN-45 cells to $30.5,0.7$, and $0 \%$; and in NCI-N87 cells to $29.2,1.6$, and $0 \%$. Exposure to docetaxel $(3,30,300 \mu \mathrm{g} / \mathrm{ml})$ reduced cell viability in AGS cells to 85.7, 47.6, and 52.4\%; in MKN-45 cells to $66.1,27.4$, and $17.7 \%$; and in NCI-N87 cells to 87.7, 57.5, and 58.8\%. Proliferation decreased in AGS cells to $27.4,8.2$, and $0 \%$; in MKN-45 cells to 29.1, 2.1, and $0 \%$; and in NCI-N87 cells to 8.8, 4.9, and $0 \%$.

Tumor growth and dissemination

For the in vivo experiments in mice, we examined the antitumor effects of cetuximab and carboplatin in the human K-ras wild-type gastric cancer cell lines MKN-45 (negative for EGFR cell surface expression) and NCI-N87 (positive for EGFR cell surface expression). The tumor 
A

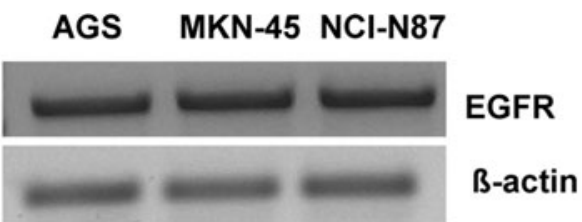

B

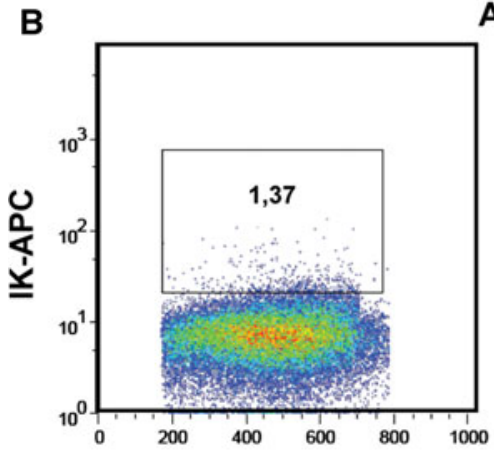

AGS

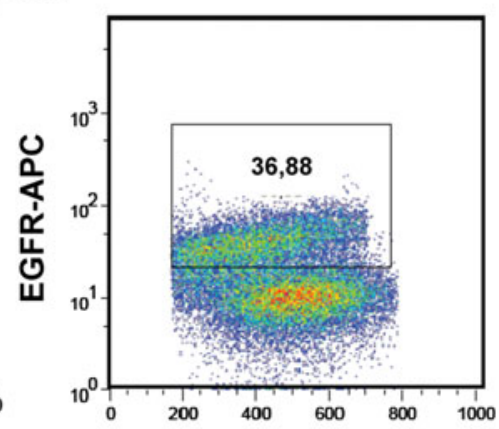

MKN-45
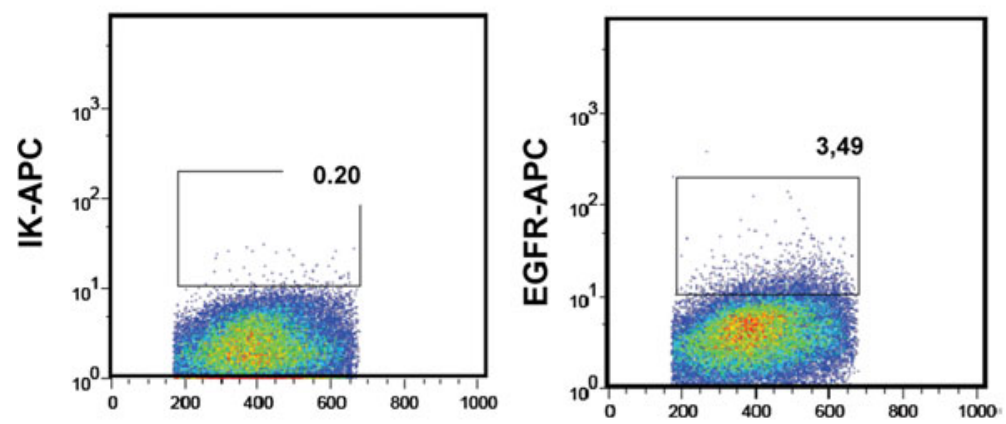

NCI-N87
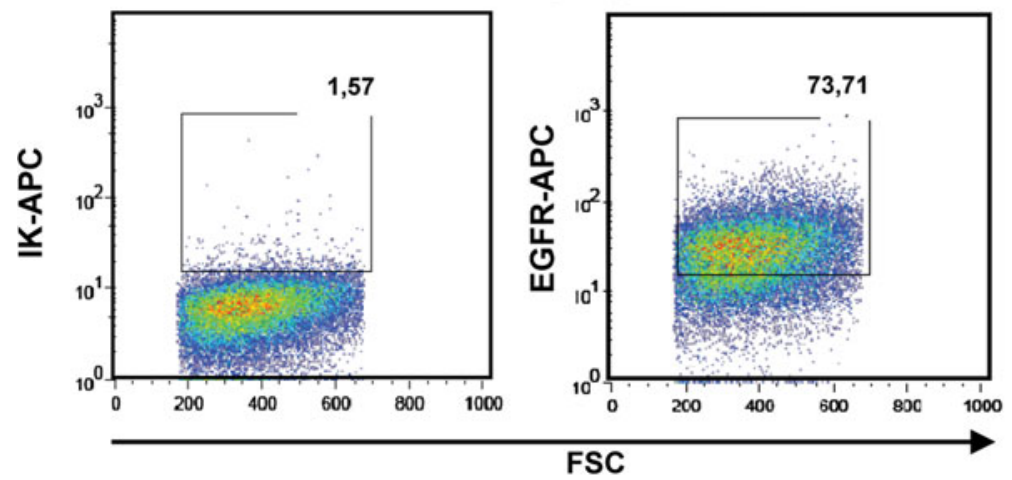

D
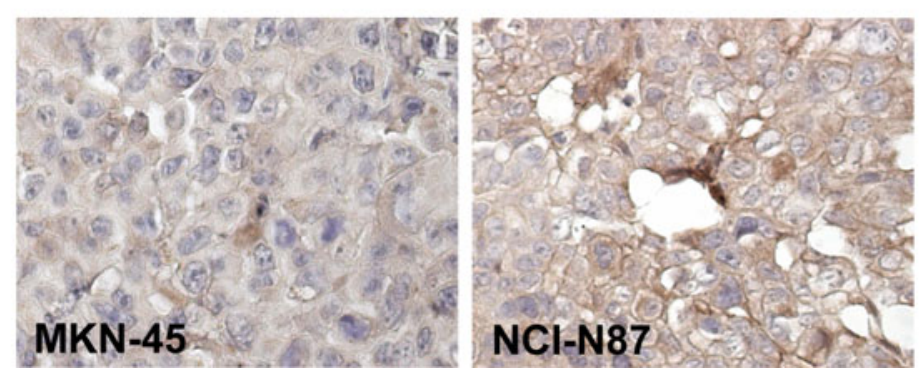

C

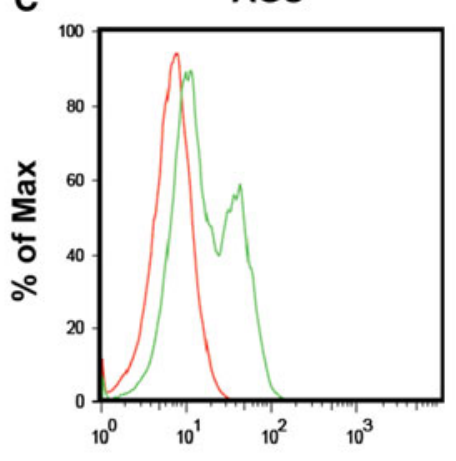

MKN-45
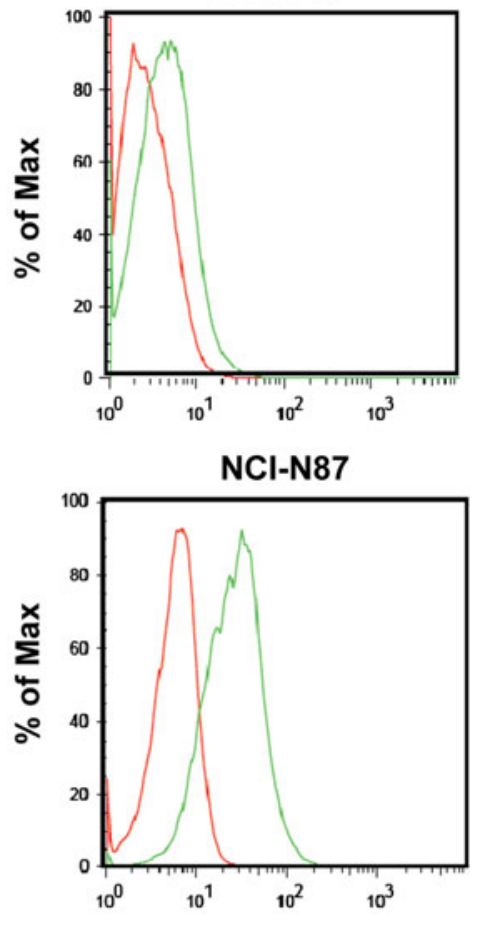
4 Fig. 1 Expression of epidermal growth factor receptor $(E G F R)$ in gastric cancer cell lines (AGS, MKN-45, and NCI-N87). a Reverse transcriptase polymerase chain reaction (RT-PCR); mRNA of EGFR was found in all gastric cancer cell lines. b, c Cell surface EGFR expression measured by flow cytometry in representative cell samples of individual gastric cancer cell lines: AGS (upper panels), MKN-45 (middle panels), NCI-N87 (bottom panels). Cells were treated with the specific anti-human EGFR monoclonal antibody (mAb) or, for reference, an isotype-matched control antibody. b Percentages of EGFR-positive cells are shown for each cell line (dot plot, middle column), the references for each cell line are shown opposed (dot plot, left column). $\mathbf{c}$ The levels of EGFR expression are shown for each cell line. Histograms indicate the mean fluorescence intensity for cell samples of individual cell lines; the $Y$-axis indicates the normalized number of events. MKN-45 cells were found to be EGFR-negative because the right curve (cells treated with anti-EGFR antibody) overlapped with the left curve (cells incubated with control antibody). d Immunohistochemical detection of EGFR in tumors derived from MKN-45 (left) and NCI-N87 (right), confirming cell surface expression on NCI-N87 cells and revealing cytoplasmic EGFR protein detection in MKN-45 cells. The magnification is $400 \times$

take rate after the implantation of viable donor tumor fragments into the distal stomach was $100 \%$ for both cell lines. Dislocation of tumor fragments from the orthotopic implantation site was not observed.

\section{Tumor volume}

The volume of tumors derived from the poorly differentiated MKN-45 cell line during the observation period is shown in Fig. 3a, with a mean tumor volume of $655.9 \pm 330.2 \mathrm{~mm}^{3}$ in the control group. In vivo treatment with either cetuximab, carboplatin, or the combination of both agents did not reduce the volumes of orthotopic gastric MKN-45 cancers $(608.4 \pm 241.5,699.5 \pm 231.1$, and $783.1 \pm 393.2 \mathrm{~mm}^{3}$, respectively).

Implanted NCI-N87 tumor fragments grew to well-differentiated adenocarcinomas with a mean tumor volume of $1125 \pm 448.6 \mathrm{~mm}^{3}$ in control animals (Fig. 3b). Cetuximab reduced the tumor volume to $453.4 \pm 286.6 \mathrm{~mm}^{3}$ $(p<0.05)$. The mean NCI-N87 tumor volume in animals treated with carboplatin was $908.4 \pm 384.5 \mathrm{~mm}^{3}$ and the combination of cetuximab with carboplatin resulted in a reduced tumor volume of $292.3 \pm 252.9 \mathrm{~mm}^{3}(p<0.05$ vs. control and vs. carboplatin monotherapy).

\section{Dissemination}

Local infiltration to adjacent structures and metastatic spread into distant organs resulted in an average dissemination score of $5.82 \pm 2.27$ points in MKN-45 control animals, $4.08 \pm$ 1.52 points in animals treated with cetuximab, $5.56 \pm 1.88$ points in the carboplatin group, and $7.45 \pm 2.53$ points in animals that received cetuximab and carboplatin (Fig. 3). Local infiltration occurred predominantly to the liver and the pancreas. Distant metastasis to the lung was found in $17 \%$ of MKN-45 control animals, $17 \%$ of the cetuximab group, $25 \%$ of the carboplatin group, and $50 \%$ of the animals which received cetuximab + carboplatin. Affected lymph nodes in the liver hilum were seen in $42 \%$ of control animals, in $33 \%$ of the cetuximab group, $58 \%$ of the carboplatin group, and $42 \%$ of the cetuximab + carboplatin group. No treatment strategy resulted in a significant reduction of tumor dissemination in this cell line.

In contrast, NCI-N87 tumor-bearing mice showed a dissemination score of $11.78 \pm 4.55$ points in the control group, $8.55 \pm 4.96$ points in the cetuximab group, $7.17 \pm 3.33$ points after treatment with carboplatin, and $4.36 \pm 2.53$ points in the combination group (cetuximab + carboplatin; $p<0.05$ vs. controls; Fig. 3). Distant metastatic spread to the lung was seen in $50 \%$ of control animals, in $33 \%$ of animals treated with cetuximab, in $42 \%$ of animals in the carboplatin group, and in only $17 \%$ of animals treated with cetuximab and carboplatin.

\section{Survival}

As shown in Fig. 4, tumors derived from the MKN-45 cell line grew and spread less aggressively; $75 \%$ of the control animals survived within the observation period. Treatment with cetuximab resulted in a 14-week survival of $92 \%$, while $58 \%$ of the animals in the carboplatin group and $50 \%$ of the animals in the combination group were alive at the end of the study. The aggressive in vivo behavior of NCI-N87 tumors was associated with a low 14-week survival in the control group (25\%). Cetuximab and carboplatin increased survival to $50 \%$, and the combination of both agents led to a $33 \%$ survival. These differences between the two tumor types were not statistically significant.

\section{Microvessel density in vivo after EGFR blockade}

The MVD as a parameter of angiogenic activity was determined by immunohistochemistry, using anti-CD31 as an endothelial marker (Fig. 5a). In MKN-45 tumors, the mean MVD was unchanged in all groups (control $54.13 \pm$ 9.69/0.74 $\mathrm{mm}^{2}$, cetuximab $59.08 \pm 8.2 / 0.74 \mathrm{~mm}^{2}$, carboplatin $59.97 \pm 10.14 / 0.74 \mathrm{~mm}^{2}$, and cetuximab + carboplatin $63.94 \pm 8.71 / 0.74 \mathrm{~mm}^{2}$ ). Tumors derived from the NCI-N87 cell line had a mean MVD of $55.74 \pm 8.97 /$ $0.74 \mathrm{~mm}^{2}$ in the control group. Treatment with cetuximab alone and in combination with carboplatin significantly reduced the MVD to $29.42 \pm 8.97 / 0.74 \mathrm{~mm}^{2}$ (cetuximab) and to $29.67 \pm 5.3 / 0.74 \mathrm{~mm}^{2}$ (cetuximab + carboplatin). The mean MVD in the carboplatin group was $48.15 \pm$ $8.23 / 0.74 \mathrm{~mm}^{2}$ (Fig. 5b). 
A

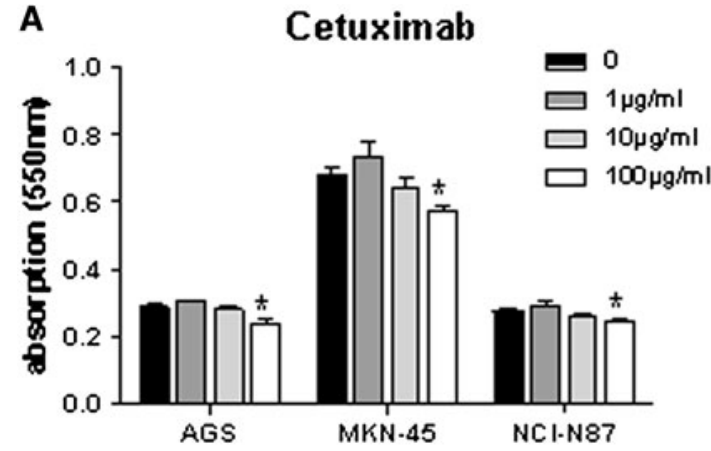

B

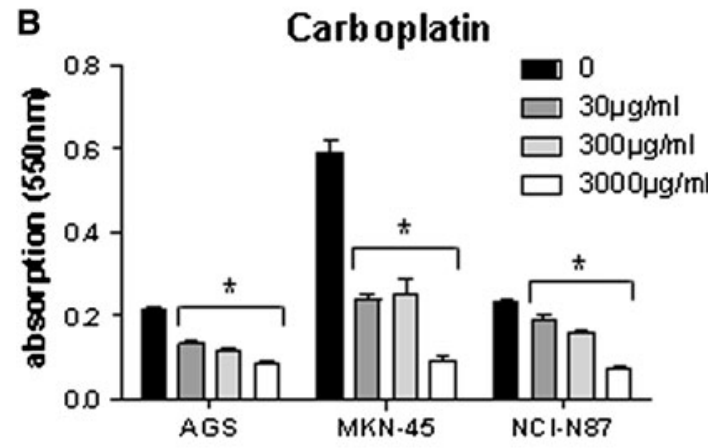

$c$

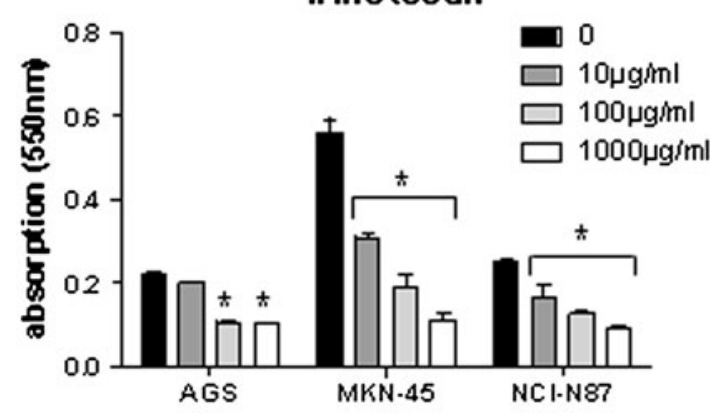

D

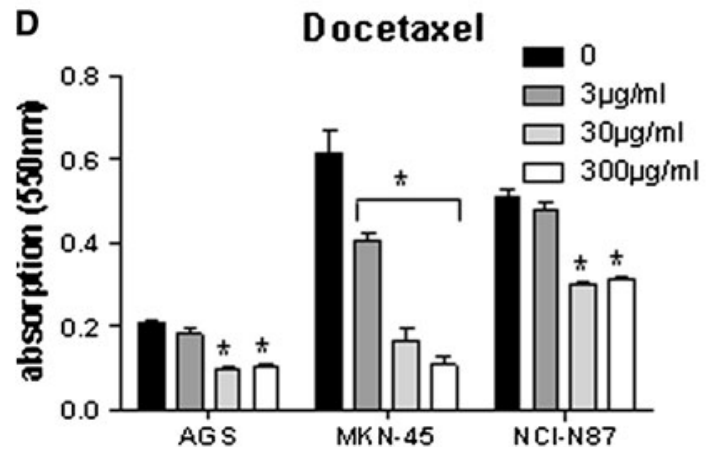

Fig. 2 In vitro effects of cetuximab and the chemotherapeutic agents carboplatin, irinotecan, and docetaxel in AGS, MKN-45, and NCIN87 human gastric cancer cell lines. a Cetuximab reduced cell viability (left panel) and proliferation (right panel) only at high

\section{Discussion}

Recently, Bang et al. [22] reported the first phase 3 trial that demonstrated a significant therapeutic effect of targeted
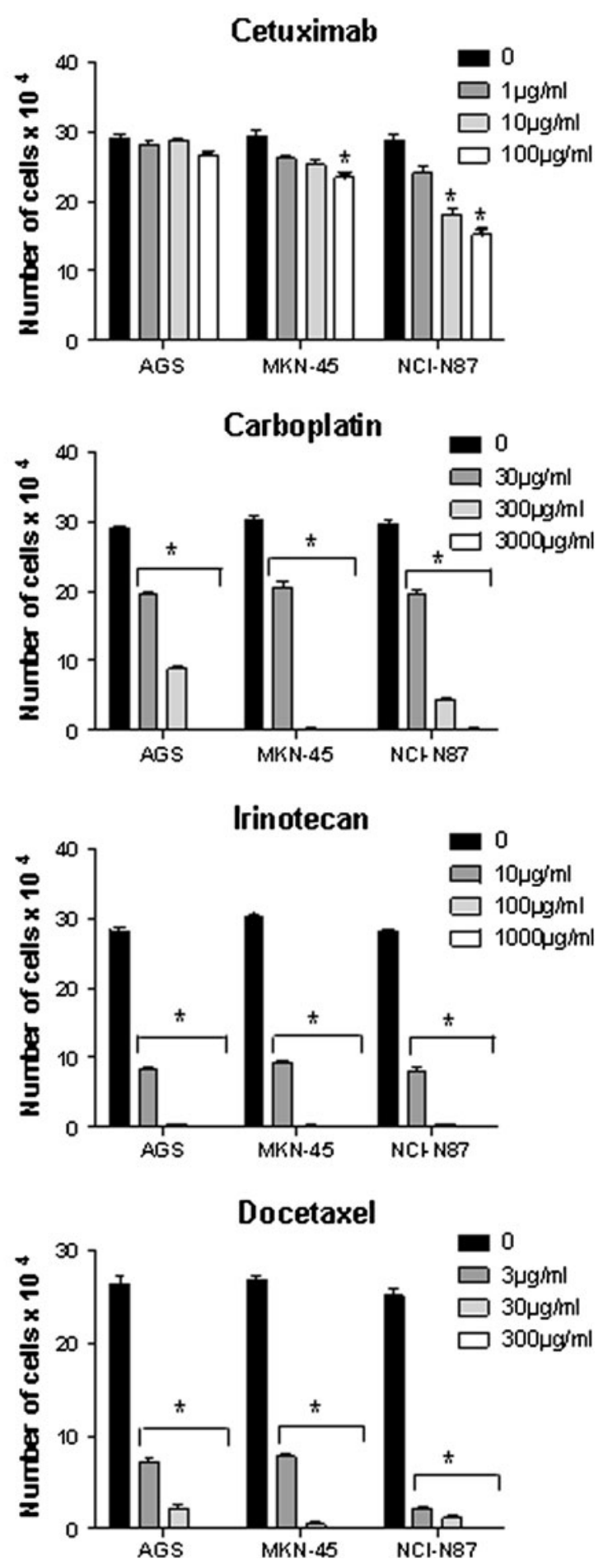

concentrations. Dose-dependent reduction of cell viability and proliferation after treatment with carboplatin (b), irinotecan (c), and docetaxel (d) even at low concentrations. Data are expressed as means \pm SEM $(* p<0.05)$

antibody therapy for gastric cancer: a combination of trastuzumab, a monoclonal antibody against EGFR2 (HER2), and chemotherapy was able to prolong survival when compared to chemotherapy alone in cancers overexpressing 


\section{A $\mathrm{MKN}-45$}
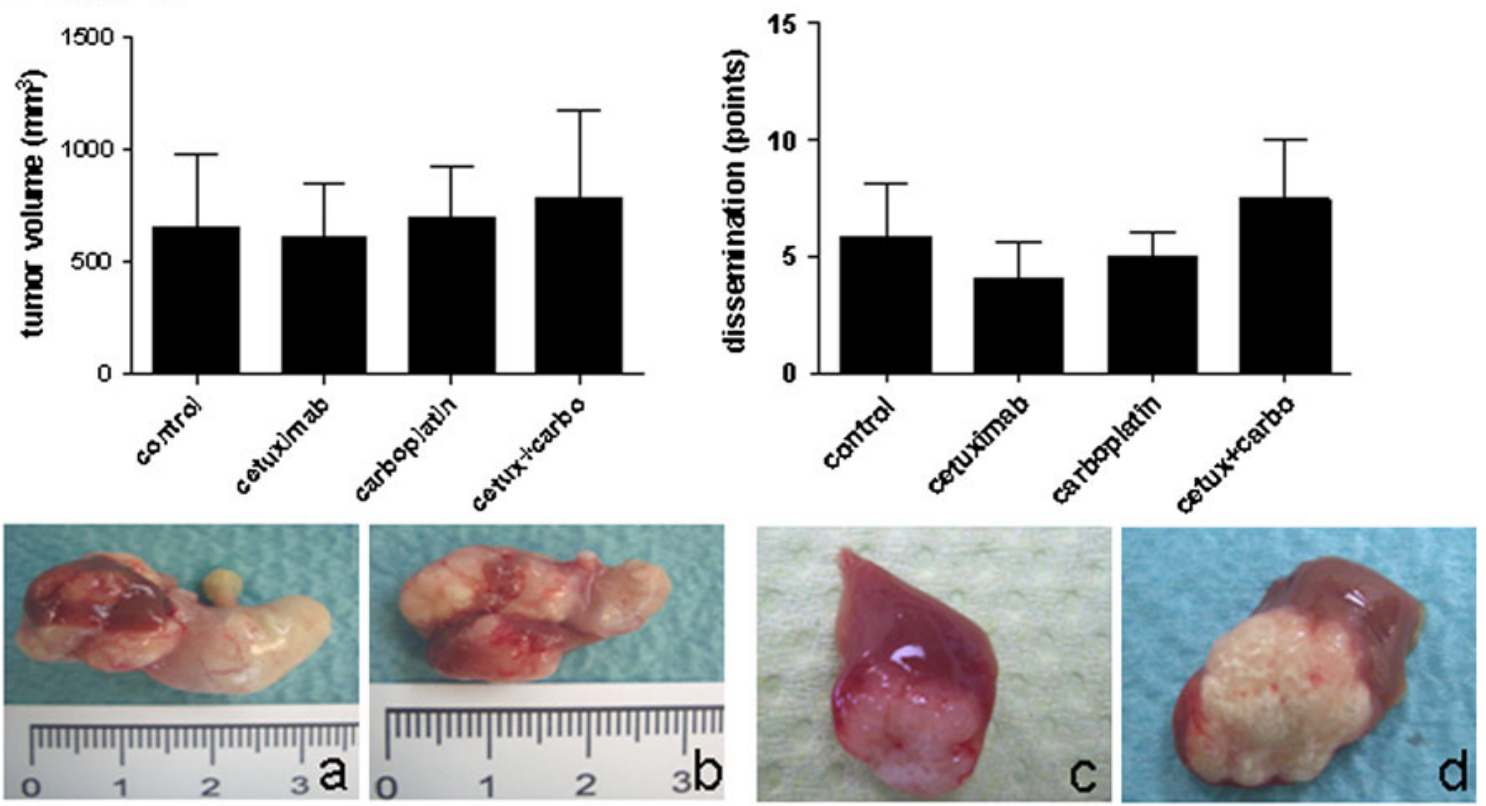

\section{B NCl-N87}
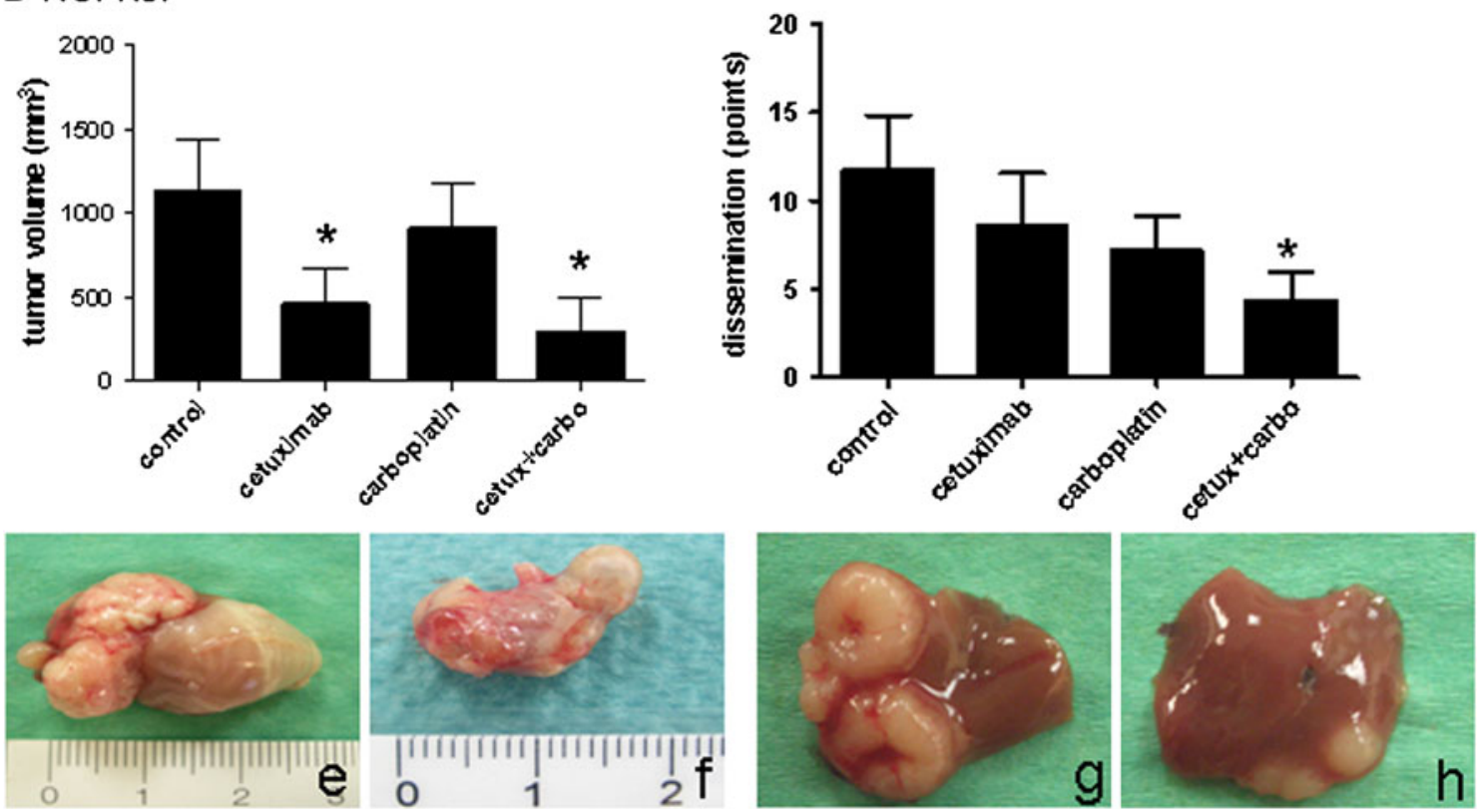

Fig. 3 Comparison of the antitumor effects of cetuximab and carboplatin, and the combination of both agents, on the growth and dissemination of orthotopic gastric cancer xenografts in nude mice. Primary tumor volume and dissemination of MKN-45 (A), and NCIN87 tumors (B) with representative tumors from MKN-45 (a) control

group, (b) cetuximab group, and NCI-N87 (e) control group, (f) cetuximab group $(* p<0.05)$. Representative liver metastases are shown for MKN-45 $(c)$ control group, $(d)$ cetuximab group, NCIN87 $(g)$ control group, and $(h)$ cetuximab group

HER2. As in breast cancer, the expression of HER2 was a prerequisite for the preclinical as well as clinical efficacy of HER2 targeting.

Several agents have been developed for targeting EGFR, including monoclonal antibodies and thyrosine kinase inhibitors. One of these antibodies, cetuximab, exerts its antitumor efficacy by multiple mechanisms that include the inhibition of cell cycle progression by arrest in the G1phase and decreased cell number in the S-phase. Cell cycle arrest in the G1-phase also induces apoptosis by the induction and activation of proapoptotic molecules [23]. Cetuximab was approved for the treatment of patients with 

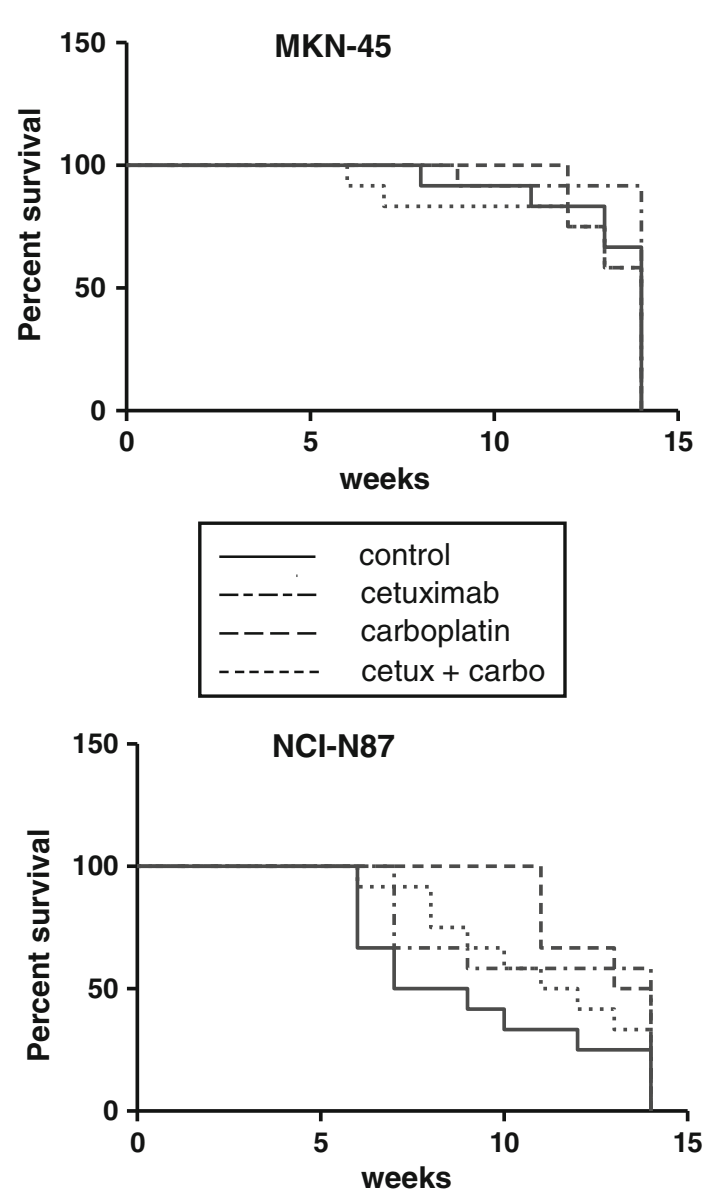

Fig. 4 Kaplan-Meier survival curves showing the effects of cetuximab and carboplatin on the survival of nude mice bearing orthotopic MKN-45 and NCI-N87 xenografts. While there was no therapeutic effect on animals with EGFR-negative MKN-45 tumors, a tendency towards increased survival (which did not reach statistical significance) was observed in treated animals with EGFR-positive NCIN87 tumors

advanced colorectal cancer and also for the treatment of squamous cell carcinoma of the head and neck. In addition, cetuximab has been investigated in multiple phase II and III studies in unselected patients with lung, gastric, esophageal, and pancreatic cancer [24-26]. However, only a subset of patients responded to cetuximab. In all of the carcinomas investigated, the efficacy of cetuximab was not associated with the EGFR cell surface expression levels detected by immunohistochemistry. In patients with colorectal carcinoma, however, intrinsic activation of the EGFR signaling pathway by activating mutations of K-ras or BRAF was recently identified as a marker for patient selection, as K-ras and BRAF mutations were associated with complete inefficacy of cetuximab treatment [16]. On the other hand, more recent data suggestthat the BRAF mutation status is not a strong predictive biomarker for cetuximab activity [27] and should therefore not be used as a selection factor for treatment with EGFR-targeted agents in patients with wild-type K-ras tumors.

There are currently ongoing clinical trial programs of EGFR targeting in unselected patients with gastric cancer, but, to our knowledge, the relationship of cetuximab efficacy to cell surface EGFR expression and mutational status has not been sufficiently tested in preclinical models. The anti-tumor effects and mechanisms of cetuximab have already been described in xenograft models of gastric cancer [28, 29], but the present study is the first to have employed an orthotopic animal model of gastric cancer which recapitulates not only local tumor growth but also the process of metastasis. We here initially investigated 3 cell lines, but later excluded the AGS cell line from in vivo testing because of its heterogeneity for EGFR expression and presence of mutated K-ras. Thus, we report here on two cell lines with an interesting phenotype, both wild-type K-ras and BRAF, with NCI-N87 expressing EGFR on the surface, in contrast to MKN-45, which lacks cell surface EGFR expression, but which shows the presence of EGFR transcripts at the mRNA level and also shows cytoplasmic antibody staining. Carboplatin was preferred for combination therapy over cisplatin, due to personal experience with the drug in animal studies and because carboplatin has been described as a second-generation analogue of cisplatin with less nephro-, neuro-, and ototoxicity, while it is at least as active as cisplatin at its maximum tolerated dose [30, 31].

While the cell line MKN-45 was slightly sensitive to cetuximab in vitro at the highest concentration of $100 \mu \mathrm{g} /$ $\mathrm{ml}$, as well as being responsive to carboplatin, in vivo findings showed that tumors originating from these cells were completely resistant to cetuximab and carboplatin either alone or in combination, suggesting that the cytoplasmic expression of the EGFR was irrelevant for the in vivo efficacy of EGFR targeting. Such a discordance between the in vitro and in vivo activities of cetuximab has previously been reported in preclinical studies of other tumor types, such as colorectal cancer and thyroid cancer [14, 32]. The EGFR-positive cell line NCI-N87, however, responded to cetuximab as well as carboplatin in vitro and in vivo, with evidence for in vivo synergy between both agents. These results are consistent with other studies demonstrating that the antitumor activity of several anticancer agents increases when combined with cetuximab [5, 9, 25, 32].

In addition to the primary efficacy observation, we also observed that treatment with cetuximab significantly reduced MVD in the EGFR-positive NCI-N87 tumors but not in the EGFR-negative MKN-45 tumors. In contrast, carboplatin alone was found to reduce tumor growth, but not MVD, in NCI-N87 tumors, and combination treatment led to a further reduction of the tumor volume, but had no 
A

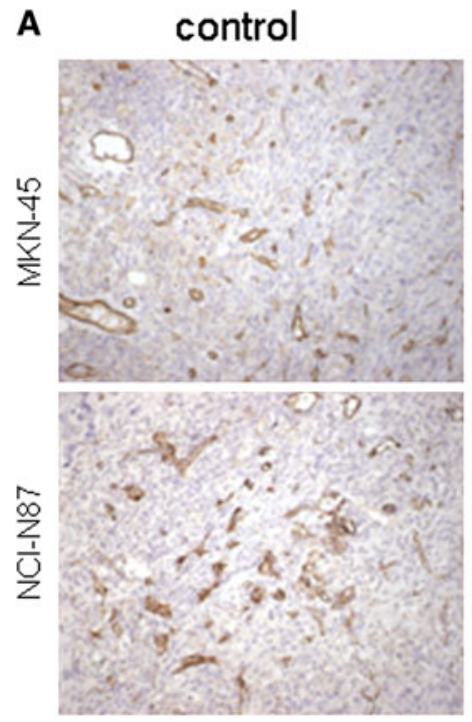

cetuximab
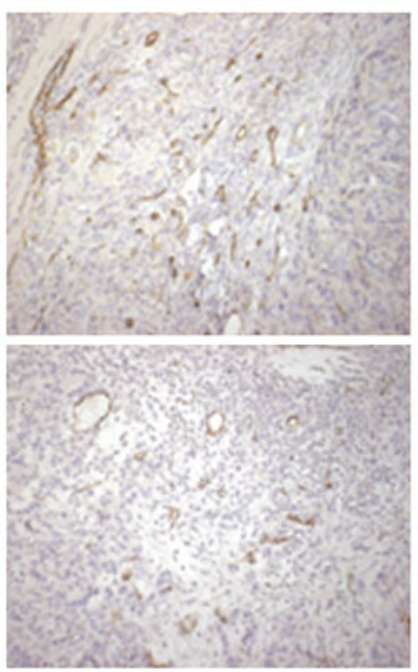

carboplatin
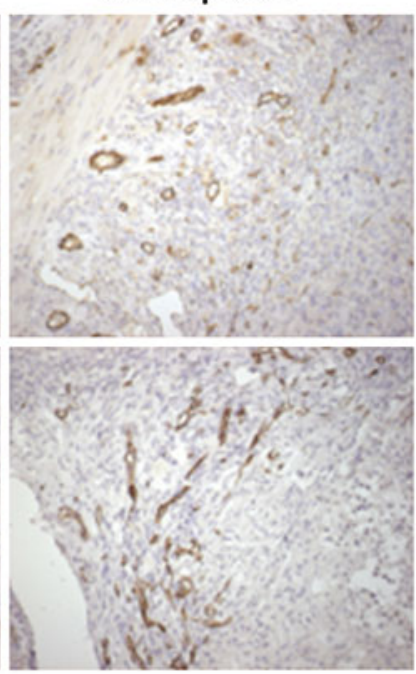

cetux+carbo
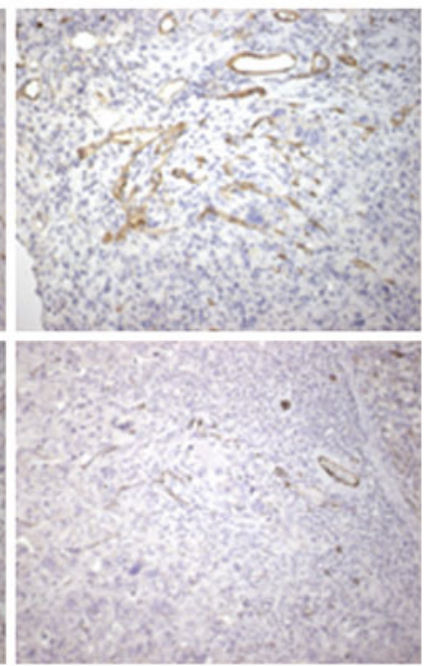

B

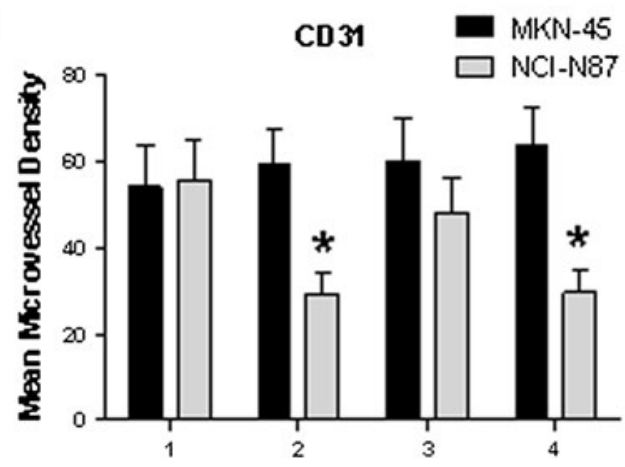

Fig. 5 Immunohistochemical analysis of microvessel density (MVD). Tumor sections from animals treated with cetuximab or carboplatin, or both agents, were immunostained for CD31 to quantify the MVD. a Representative staining from each group and cell line. $\times 200$.

additional effect on MVD, indicating that the antiangiogenic impact is exerted by cetuximab and not by carboplatin. It has previously been described that the vascular endothelial growth factor (VEGF) and EGFR pathways are closely related in solid tumors, as EGF signaling is able to induce VEGF expression. Blockade of EGFR with cetuximab resulted in the downregulation of proangiogenic mediators, including VEGF, accompanied by reductions in MVD and metastases in tumor xenografts of transitional cell carcinoma, colorectal cancer, and thyroid carcinoma $[18,32,33]$.

In conclusion, the present report has demonstrated that therapy with cetuximab alone and in synergy with carboplatin resulted in decreases of tumor size, metastatic spread, and MVD in NCI-N87 tumors with EGFR cell surface expression and absence of mutations in BRAF and $\mathrm{K}$-ras, whereas cetuximab had minimal in vitro effect and no in vivo treatment efficacy in tumors derived from MKN45 , in which the phenotype was also BRAF and K-ras wildtype, but which had only weak cytoplasmic EGFR protein b Quantification of CD31 by vessel count under light microscopy. 1 Control, 2 cetuximab, 3 carboplatin, 4 cetuximab + carboplatin. MVD was significantly reduced in NCI-N87 tumors treated with cetuximab and the combination of cetuximab with carboplatin. ${ }^{*} p<0.05$

expression. Further, there was no in vitro effect on AGS cells displaying mutated K-ras. These results suggest that patient selection based on K-ras mutation as well as EGFR surface expression could prove useful in clinical trial programs with EGFR targeting in patients with gastric cancer.

Acknowledgments We thank Dr. Ulrike Erben, Charité, Department of Gastroenterology for her expertise, and we thank Marco Arndt and Sonja Dullat for their technical support.

\section{References}

1. Kamangar F, Dores G, Anderson WF. Patterns of cancer incidence, mortality, and prevalence across five continents: defining priorities to reduce cancer disparities in different geographic regions of the world. J Clin Oncol. 2006;24:2137-50.

2. Alberts SR, Cervantes A, van de Velde CJ. Gastric cancer: epidemiology, pathology and treatment. Ann Oncol. 2003;14(Suppl 2):ii31-6.

3. Galizia G, Lieto E, Orditura M, Castellano P, Mura AL, Imperatore V, Pinto M, Zamboli A, De Vita F, Ferraraccio F. 
Epidermal growth factor receptor (EGFR) expression is associated with a worse prognosis in gastric cancer patients undergoing curative surgery. World J Surg. 2007;31:1458-68.

4. Anzai H, Kitadai Y, Bucana CD, Sanchez R, Omoto R, Fidler IJ. Expression of metastasis-related genes in surgical specimens of human gastric cancer can predict disease recurrence. Eur J Cancer. 1998;34:558-65.

5. Pinto C, Di Fabio F, Barone C, Siena S, Falcone A, Cascinu S, Rojas Llimpe FL, Stella G, Schinzari G, Artale S, Mutri V, Giaquinta S, Giannetta L, Bardelli A, Martoni AA. Phase II study of cetuximab in combination with cisplatin and docetaxel in patients with untreated advanced gastric or gastro-oesophageal junction adenocarcinoma (DOCETUX study). $\mathrm{Br} \mathrm{J}$ Cancer. 2009;101:1261-8.

6. Saltz LB, Meropol NJ, Loehrer PJ Sr, Needle MN, Kopit J, Mayer RJ. Phase II trial of cetuximab in patients with refractory colorectal cancer that expresses the epidermal growth factor receptor. J Clin Oncol. 2004;22:1201-8.

7. Saltz LB, Lenz HJ, Kindler HL, Hochster HS, Wadler S, Hoff PM, Kemeny NE, Hollywood EM, Gonen M, Quinones M, Morse M, Chen HX. Randomized phase II trial of cetuximab, bevacizumab, and irinotecan compared with cetuximab and bevacizumab alone in irinotecan-refractory colorectal cancer: the BOND-2 study. J Clin Oncol. 2007;25:4557-61.

8. Arkenau HT. Gastric cancer in the era of molecularly targeted agents: current drug development strategies. J Cancer Res Clin Oncol. 2009;135:855-66.

9. Rivera F, Vega-Villegas ME, Lopez-Brea MF. Cetuximab, its clinical use and future perspectives. Anticancer Drugs. 2008;19:99-113.

10. Huang ZQ, Buchsbaum DJ, Raisch KP, Bonner JA, Bland KI, Vickers SM. Differential responses by pancreatic carcinoma cell lines to prolonged exposure to Erbitux (IMC-C225) anti-EGFR antibody. J Surg Res. 2003;111:274-83.

11. Overholser JP, Prewett MC, Hooper AT, Waksal HW, Hicklin DJ. Epidermal growth factor receptor blockade by antibody IMCC225 inhibits growth of a human pancreatic carcinoma xenograft in nude mice. Cancer. 2000;89:74-82.

12. Buchsbaum DJ, Bonner JA, Grizzle WE, Stackhouse MA, Carpenter M, Hicklin DJ, Bohlen P, Raisch KP. Treatment of pancreatic cancer xenografts with Erbitux (IMC-C225) anti-EGFR antibody, gemcitabine, and radiation. Int $\mathrm{J}$ Radiat Oncol Biol Phys. 2002;54:1180-93.

13. Morgan MA, Parsels LA, Kollar LE, Normolle DP, Maybaum J, Lawrence TS. The combination of epidermal growth factor receptor inhibitors with gemcitabine and radiation in pancreatic cancer. Clin Cancer Res. 2008;14:5142-9.

14. Balin-Gauthier D, Delord JP, Rochaix P, Mallard V, Thomas F, Hennebelle I, Bugat R, Canal P, Allal C. In vivo and in vitro antitumor activity of oxaliplatin in combination with cetuximab in human colorectal tumor cell lines expressing different level of EGFR. Cancer Chemother Pharmacol. 2006;57:709-18.

15. Jimeno A, Messersmith WA, Hirsch FR, Franklin WA, Eckhardt SG. KRAS mutations and susceptibility to cetuximab and panitumumab in colorectal cancer. Cancer J. 2009;15:110-3.

16. Karapetis CS, Khambata-Ford S, Jonker DJ, O'Callaghan CJ, Tu D, Tebbutt NC, Simes RJ, Chalchal H, Shapiro JD, Robitaille S, Price TJ, Shepherd L, Au HJ, Langer C, Moore MJ, Zalcberg JR. $\mathrm{K}$-ras mutations and benefit from cetuximab in advanced colorectal cancer. N Engl J Med. 2008;359:1757-65.

17. Di Nicolantonio F, Martini M, Molinari F, Sartore-Bianchi A, Arena S, Saletti P, De Dosso S, Mazzucchelli L, Frattini M, Siena $\mathrm{S}$, Bardelli A. Wild-type BRAF is required for response to panitumumab or cetuximab in metastatic colorectal cancer. J Clin Oncol. 2008;26:5705-12.
18. Perrotte P, Matsumoto T, Inoue K, Kuniyasu H, Eve BY, Hicklin DJ, Radinsky R, Dinney CP. Anti-epidermal growth factor receptor antibody C225 inhibits angiogenesis in human transitional cell carcinoma growing orthotopically in nude mice. Clin Cancer Res. 1999;5:257-65.

19. Bhargava S, Hotz B, Buhr HJ, Hotz HG. An orthotopic nude mouse model for preclinical research of gastric cardia cancer. Int J Colorectal Dis. 2009;24:31-9.

20. Hotz HG, Reber HA, Hotz B, Yu T, Foitzik T, Buhr HJ, Cortina G, Hines OJ. An orthotopic nude mouse model for evaluating pathophysiology and therapy of pancreatic cancer. Pancreas. 2003;26:e89-98.

21. Weidner N. Tumoural vascularity as a prognostic factor in cancer patients: the evidence continues to grow. J Pathol. 1998; 184:119-22.

22. Bang YJ, Van Cutsem E, Feyereislova A, Chung HC, Shen L, Sawaki A, Lordick F, Ohtsu A, Omuro Y, Satoh T, Aprile G, Kulikov E, Hill J, Lehle M, Ruschoff J, Kang YK. Trastuzumab in combination with chemotherapy versus chemotherapy alone for treatment of HER2-positive advanced gastric or gastrooesophageal junction cancer (ToGA): a phase 3, open-label, randomised controlled trial. Lancet. 2010;376:687-97.

23. Capdevila J, Elez E, Macarulla T, Ramos FJ, Ruiz-Echarri M, Tabernero J. Anti-epidermal growth factor receptor monoclonal antibodies in cancer treatment. Cancer Treat Rev. 2009;35:354-63.

24. Safran H, Suntharalingam M, Dipetrillo T, Ng T, Doyle LA, Krasna M, Plette A, Evans D, Wanebo H, Akerman P, Spector J, Kennedy N, Kennedy T. Cetuximab with concurrent chemoradiation for esophagogastric cancer: assessment of toxicity. Int $\mathrm{J}$ Radiat Oncol Biol Phys. 2008;70:391-5.

25. Han SW, Oh DY, Im SA, Park SR, Lee KW, Song HS, Lee NS, Lee KH, Choi IS, Lee MH, Kim MA, Kim WH, Bang YJ, Kim TY. Phase II study and biomarker analysis of cetuximab combined with modified FOLFOX6 in advanced gastric cancer. Br J Cancer. 2009;100:298-304.

26. Kullmann F, Hollerbach S, Dollinger MM, Harder J, Fuchs M, Messmann H, Trojan J, Gabele E, Hinke A, Hollerbach C, Endlicher E. Cetuximab plus gemcitabine/oxaliplatin (GEMOXCET) in first-line metastatic pancreatic cancer: a multicentre phase II study. Br J Cancer. 2009;100:1032-6.

27. Van Cutsem E, Kohne CH, Lang I, Folprecht G, Nowacki MP, Cascinu S, Shchepotin I, Maurel J, Cunningham D, Tejpar S, Schlichting M, Zubel A, Celik I, Rougier P, Ciardiello F. Cetuximab plus irinotecan, fluorouracil, and leucovorin as first-line treatment for metastatic colorectal cancer: updated analysis of overall survival according to tumor KRAS and BRAF mutation status. J Clin Oncol. 2011;29:2011-9.

28. Hara M, Nakanishi H, Tsujimura K, Matsui M, Yatabe Y, Manabe T, Tatematsu M. Interleukin-2 potentiation of cetuximab antitumor activity for epidermal growth factor receptor-overexpressing gastric cancer xenografts through antibody-dependent cellular cytotoxicity. Cancer Sci. 2008;99:1471-8.

29. Patel D, Bassi R, Hooper A, Prewett M, Hicklin DJ, Kang X. Anti-epidermal growth factor receptor monoclonal antibody cetuximab inhibits EGFR/HER-2 heterodimerization and activation. Int J Oncol. 2009;34:25-32.

30. Treskes M, van der Vijgh WJ. WR2721 as a modulator of cisplatin- and carboplatin-induced side effects in comparison with other chemoprotective agents: a molecular approach. Cancer Chemother Pharmacol. 1993;33:93-106.

31. Ariyoshi Y, Ota K. Preclinical and clinical evaluation of toxicity and antitumor activity of cisplatin analogues. Gan To Kagaku Ryoho. 1989;16:1379-85.

32. Kim S, Prichard CN, Younes MN, Yazici YD, Jasser SA, Bekele $\mathrm{BN}$, Myers JN. Cetuximab and irinotecan interact synergistically 
to inhibit the growth of orthotopic anaplastic thyroid carcinoma xenografts in nude mice. Clin Cancer Res. 2006;12:600-7.

33. Ciardiello F, Bianco R, Damiano V, Fontanini G, Caputo R, Pomatico G, De Placido S, Bianco AR, Mendelsohn J, Tortora G. Antiangiogenic and antitumor activity of anti-epidermal growth factor receptor C225 monoclonal antibody in combination with vascular endothelial growth factor antisense oligonucleotide in human GEO colon cancer cells. Clin Cancer Res. 2000;6:3739-47. 